\title{
Fluoridation Practices - A Missing Link in the Vaccine Autism Connection?
}

\author{
Author: \\ Robert Jay Rowen, MD, sole author \\ Private Medical Practice, Santa Rosa, \\ California \\ 2200 County Center Dr. Ste C \\ Santa Rosa, CA 95403 USA \\ Email: drrowen@att.net
}

**Declarations $* *$

Ethics approval and consent to participate: Not applicable

Consent for publication: Not applicable

Availability of data and material: not applicable

Competing interests: none

Funding: self

Authors' contributions: Rowen 100\%

Acknowledgements: Dedicated to the thousands of families worldwide, which have been devastated by ASD, and those parents working tirelessly and selflessly to halt the epidemic. Special mention to those parents of injured children who personally brought my attention to an apparent link between vaccination and the development of injury to their child.

Authors' information: Dr. Rowen is in private medical practice. His specialty is integrative medicine.

\begin{abstract}
:
Autism Spectrum Disorder (ASD) rates around the world are skyrocketing for unknown reasons. Parents have fingered vaccines but studies have failed to confirm a link. Concurrently, aluminum, from vaccine adjuvants, has been found actively transported to the brains of animals inciting inflammation. Fluoride has been implicated in children's brain dysfunction, and, fluoride has been shown to potentiate aluminum toxicity. No vaccine study to date has controlled for a practice widespread around the world - water fluoridation. Autism is more prevalent in United States cities that fluoridate their water supplies, and less prevalent in rural nonfluoridated areas even with high vaccination rates. This manuscript presents basic science and a hypothesis that fluoride could be potentiating the toxic neurological effects of aluminum in vaccines. This effect could lead to skewed data and confounding vaccine safety statistics by omission of this critical control factor.
\end{abstract}

Keywords: autism, autism spectrum disorders, fluoride, aluminum, vaccines 


\subsection{Background:}

There is no accepted scientific explanation for the huge rise in ASD incidence. Parents and many professionals have long suspected vaccines, but the medical literature is full of reports that vaccines are not the cause. However, in many reports, the vaccine recipients are compared to adjuvants and "non-antigen" recipients for controls. This begs the question if such "safety" studies should have been accepted for publication at all.

Many researchers have pondered the issue considering toxins, diet, genetics, and especially the hot vaccine controversy. Some studies implicate vaccines or thimerosal therein. One review found a high correlation between mercury exposure and autism (1). Another review totes "shifting hypotheses" in an unproven vaccine story (2). (For example, the National Academy of Sciences reported no apparent connection between vaccines and autism (3).) The United States has seen enormous political fights regarding mandatory school vaccines. Many parents attended legislative sessions (California SB 277 hearings) contemplating forced vaccination. They presented their autistic children, demanding no forced vaccinations. Medical professionals have told many parents that since the regression to autism occurred so much later than the vaccines there are no connections. Consequently, parents' experiences/observations are discarded. The "no-connection theory" remains the prevailing paradigm regarding vaccination. Could there be a missed vaccine/autism connection missed by synergism of toxins?

Toxin synergism is especially hard to study. There are too many confounding factors. However, we have clues about toxin synergism from study in which the combined LD1 each of mercury and lead killed $100 \%$ of animals (4).

This commentary proposes a theory connecting dots in vaccine/toxin/autism research. That is - the synergism of toxins, particularly related to fluoride and aluminum. Synergism of toxins has never been studied in any report on vaccines and autism.

\subsection{The Toxins: Aluminum and}

\section{Fluoride:}

The maximum FDA guideline for aluminum received in an IV is $25 \mathrm{mcg}$ per day. The suggested aluminum per $\mathrm{kg}$ of weight permitted $\mathrm{n}$ is up to $5 \mathrm{mcg}$. (so a 5 pounds baby $(2.27 \mathrm{~kg}$ ) should get no more than $11 \mathrm{mcg}$ of aluminum per day.) Anything that has more than $25 \mathrm{mcg}$ of aluminum is *supposed* to have a label that says:

WARNING: This product contains aluminum that may be toxic. Aluminum may reach toxic levels with prolonged parenteral administration if kidney function is impaired. Premature neonates are particularly at risk because their kidneys are immature, and they require large amounts of calcium and phosphate solutions, which contain aluminum.

Research indicates that patients with impaired kidney function, including premature neonates, who receive parenteral levels of aluminum at greater than 4 to 5 [micro] $\mathrm{g} / \mathrm{kg} /$ day accumulate aluminum at levels associated with central nervous system and bone toxicity. Tissue loading may occur at even lower rates of administration. (5) 
Simple math provides the following FDA guidelines for maximum exposure to aluminum for healthy individuals:

8 pound, baby: $18.16 \mathrm{mcg}$ of aluminum

15 pound, baby: $34.05 \mathrm{mcg}$ of aluminum

30 pound, toddler: $68.1 \mathrm{mcg}$ of aluminum

50 pound, child: 113 mcg of aluminum

350 pound adult: $794.5 \mathrm{mcg}$ of aluminum

\subsection{Aluminum in vaccines:}

Hepatitis B - $250 \mathrm{mcg}$

DTaP - depending on the manufacturer, ranges from 170 to $625 \mathrm{mcg}$

Pneumococcus - $125 \mathrm{mcg}$

Hepatitis A - 250 mcg

Pentacel (DTaP, HIB and Polio combo vaccine) $-330 \mathrm{mcg}$

Pediarix (DTaP, Hep B and Polio combo vaccine) $-850 \mathrm{mcg}$

Hib (PedVaxHib brand only) - $225 \mathrm{mcg}$ per shot

HPV -225 mcg

At birth, most children are given the hepatitis B vaccination, which contains $250 \mathrm{mcg} \mathrm{Al}$. This is some 14 times FDA safety guidelines for a day.

At well-child check-ups, it's common for 2 month, 4 month, 6 month etc., appointments to include up to 8 vaccinations that add up to more than $1,000 \mathrm{mcg}$ of aluminum. By FDA guidelines, that amount isn't even safe for a 350-pound adult. Many children get up to 8 vaccinations a visit several times a year!
As early as 1996 The AAP (American Academy of Pediatrics) was warning about the potential for Al toxicity in children from various routes including oral, IV and even bladder irrigation. The report warned of bone build up and brain toxicity, complicated greatly in the presence of renal compromise (6). Since, there has been compelling research published on the magnitude of the potential problem.

Shaw's group has recently reported on aluminum as a vaccine containing neurotoxin (7). His group reported: "(i) children from countries with the highest ASD prevalence appear to have the highest exposure to $\mathrm{Al}$ from vaccines; (ii) the increase in exposure to $\mathrm{Al}$ adjuvants significantly correlates with the increase in ASD prevalence in the United States observed over the last two decades (Pearson $\mathrm{r}=0.92, \mathrm{p}<0.0001$ ); and (iii) a significant correlation exists between the amounts of $\mathrm{Al}$ administered to preschool children and the current prevalence of ASD in seven Western countries, particularly at 3-4 months of age (Pearson $\mathrm{r}=0.89-0.94, \mathrm{p}=0.0018-0.0248) . "(8)$

Aluminum has recently been shown to be taken up by lymphoid cells and translocated to the brain by a "Trojan Horse" mechanism (9). Gherardi's group warns of long term slow brain accumulation of aluminum from adjuvants: "This strongly suggests that long-term adjuvant biopersistence within phagocytic cells is a prerequisite for slow brain translocation and delayed neurotoxicity."

Inbar's group recently reported that aluminum adjuvant alone, in amounts "equivalent to human exposure", induced behavioral abnormalities in female mice, 
whether administered as adjuvant alone or in the intact vaccine (10). They concluded, "It appears that Gardasil via its $\mathrm{Al}$ adjuvant and HPV antigens has the ability to trigger neuroinflammation and autoimmune reactions, further leading to behavioral changes."

A comprehensive review of aluminum in vaccines by Miller (11) raises concerns of safety beyond reasonable doubt. He cites: "Recent data by Perricone et al. (12) showed that aluminum adjuvants in vaccines have been linked to multiple sclerosis, systemic lupus erythematosis, chronic fatigue syndrome, Gulf War syndrome, macrophagic myofasciitis, arthritis, and autoimmune/inflammatory syndrome induced by adjuvants (ASIA syndrome), an autoimmune disease with neurological and cognitive manifestations. Clinical symptoms associated with vaccineinduced autoimmunity can take months or years to manifest, much longer than the time intervals utilized in most vaccine safety studies." (emphasis added).

\subsection{Fluoride and neuro- development:}

The Harvard School of Public health published a meta-analysis of fluoride exposure in Chinese children and IQ. It concluded, "The results support the possibility of an adverse effect of high fluoride exposure on children's neurodevelopment. Future research should include detailed individual-level information on prenatal exposure, neurobehavioral performance, and covariates for adjustment."(13)

The same group further reported that Chinese community children "with stable lifetime fluoride exposures supports the notion that fluoride in drinking water may produce developmental neurotoxicity, and that the dose-dependence underlying this relationship needs to be characterized in detail."(14)

A 2009 study supports these findings: "However, these aspects were more pronounced in animals given fluoride and aluminum together. Histological evidence showed deprival of neuronal integrity with higher magnitude in concurrent fluoride and aluminum exposure, as compared to fluoride alone. Thus, it can be concluded that aluminum appears to enhance the neurotoxic hazards caused by fluoride."(15)

Attention deficit hyperactivity disorder (ADHD) has features common to autism including: hyperactivity, impulsivity, sensory processing, behavior problems, impaired social skills, and symptoms that are inappropriate for developmental level (16). A USA report links the highest rates of ADHD to states with the most artificially fluoridated water: "State prevalence of artificial water fluoridation in 1992 significantly positively predicted state prevalence of ADHD in 2003, 2007 and 2011, even after controlling for socioeconomic status." (17)

\subsection{Fluoride likely compounds Al} toxicity:

A 1998 animal study found that the presence of fluoride in drinking water enhanced aluminum uptake into the brains of rats and subsequent neurological deterioration (18). Aluminum fluoride $\left(\mathrm{AlF}_{3}\right)$ was found more toxic than sodium fluoride at equivalent fluoride ion doses. IgM intruded into the brains of the 
afflicted animals, all suggesting synergism of the two toxic elements. An Israeli report published online (19) found "high concentrations" of aluminum ion when aluma particles were bathed in water with fluoride concentrations at $0.1 \mathrm{M}$.

Sodium fluoride is "corrosive to aluminum (20)." Trace amounts (microg $\mathrm{g}(-1)$ quantities) of fluoride ion are found to catalyze the dissolution of metallic aluminum in very slightly acidic or alkaline aqueous media (21). This level has long been considered the "optimal" level of fluoride in municipal water.

Additionally, fluoride and/or its reactive products are known to leach other toxic metals out of pipes including lead and metallic copper (22), both of which are known neurotoxins. The presence of fluoride in a child from whatever source could be a heretofore-unknown catalyst, greatly potentiating metal (aluminum) toxicity respective to vaccines.

Most cities use fluoride compounds considered even more toxic than sodium fluoride to treat water - silicofluorides as these are cheaper products. A recent review article (23) on environmental pollutants and infant mortality points out that silicofluorides are of significantly greater reactivity with aluminum than sodium fluoride.

Silicofluoride induces a chemical hydrolysis of aluminum oxide by the following equation: $\mathrm{H}_{2} \mathrm{SiF}_{6}+\mathrm{Al}_{2} \mathrm{O}_{3}+3$ $\mathrm{H}_{2} \mathrm{O} \rightarrow 2 \mathrm{AlF}_{3}+\mathrm{SiO}_{2}+4 \mathrm{H}_{2} \mathrm{O}$. This is an exothermic reaction, and hence would be expected to spontaneously occur in any situation where alum meets with such a fluoride compound, inclusive of in vivo.

Varner (18) reported aluminum fluoride to be more neurologically toxic than fluoride itself. Children receiving aluminum by injection, and exposed to such silicofluorides in drinking water, therefore, might be expected to develop more of the more toxic $\mathrm{ALF}_{3}$ moiety over time, placing them at greater risk of neurological injury.

Summary - The aluminum/fluoride interaction is disturbing. Aluminum is a constituent of many mandatory vaccines as alum particulate adjuvants. Fluoride appears to enhance its toxicity. Aluminum is highly connected to neural toxicity, as is fluoride itself. Use of vaccines containing aluminum adjuvants appears highly significantly associated with autism in developed countries. This begs the question, "Could fluoride alter alum to make it more neurotoxic than without fluoride?"

\subsection{Autism trends in the United States and the exposure to fluoride}

It is reasonable to assume that there is close to universal compliance with vaccine guidelines in the USA for a broad general population. We should then look to geographical areas of autism occurrence to determine if fluoride exposure could be a variable factor.

1). Autism is more common in cities over rural areas (24). 2). Cities with among the highest reported rates of autism are: Los Angeles, San Francisco, Chicago, Salt Lake City, Minneapolis, Pittsburgh, and parts of New York. 3). All of these cities add fluoride to their water. 4). Fluoride has been added to the list of direct neurotoxins by authorities (25). $5)$. Fluoride has been shown to lower the IQ of children (26) and is associated with an increased prevalence of hyperactivity, part of the autism spectrum of disorders 
(27). 6). Van Meter's group found clustering of autism in California cities. While the authors considered environmental causes, these were discounted; and the authors attributed the findings to educational status (28). However, the clusters were largely in California cities with fluoridated water (Los Angeles and vicinity, Bay Area, etc.), which environmental toxic factor was not considered in the report.

Aluminum is carried by a "Trojan Horse" mechanism, from vaccine injection sites to the brain by the immune system (9). (Aluminum is taken up in the brain, progressively accumulates, and induces inflammation.) The authors state: "A Lot Must be Done to Understand How, in Certain Individuals, Alum-Containing Vaccines may Become Insidiously Unsafe". Fluoride could be an inciting factor.

I have personally received messages from doctors in third world countries perplexed by the huge rise in autism amongst peoples who never experienced the condition before vaccinations arrived. These include Nigeria, India, and Egypt. The doctors universally blame the huge push of vaccines into previously "virgin" peoples, virgin to both vaccines and to autism. These countries do not have national fluoridation implementation, as do countries like the USA. They also are not reported to have as much autism as do Western countries. (For example, India's autism prevalence is reported as about 1 in 250, and was not believed to even exist in India as late as the 1980s. (29)) The absence of fluoridation might be protecting their vaccinated population.

Poor vaccine controlling plagues autism research. From Inbar (10), "To date most human vaccine trials utilize aluminum (Al) adjuvants as placebos despite much evidence showing that $\mathrm{Al}$ in vaccine-relevant exposures can be toxic to humans and animals." Even the FDA documents that severe swelling and erythema is non-existent in vaccine saline controls vs. active Gardasil vaccine or its aluminum containing adjuvant used as control (30). There has not been a vaccine safety study that includes fluoride exposure as a control.

(Personal note - Additionally, there has never been a study on thousands of children fully vaccinated vs. a like number totally unvaccinated to determine allcause morbidity and mortality. Studies have examined the alleged deleterious effects of vaccines on children and come up with conflicting results. For example, Bach suggested the disappearance of common illness has led to the rise of chronic immune disorders (31). Other reports contradict his findings (32).)

In America, neurodevelopmental disorder rates are skyrocketing. This is especially true in cities in contrast to the USA's "rural south", where there are plenty of vaccines, but less fluoridation. The Amish people of the Pennsylvania/Ohio area have little autism, and their well water carries little fluoride. Their vaccination rates are far lower than in conventional populations (33).

Countless parents visiting our outpatient office have insisted that their child was never the same after vaccination (and many apparent vaccine affected adults as well). 


\subsection{Presentation of the hypothesis:}

"Vaccine research is compromised by overt failure to control for synergistic toxins, particularly fluoride and aluminum."

\subsection{Testing the hypothesis:}

Testing the fluoride hypothesis is mechanically easy. However, it may prove politically difficult considering high degrees of political, emotional, economic, and corporate vested interests in maintaining the current paradigm. Vaccine manufacturers have been given carte blanche immunity (cannot be sued for vaccine induced injuries) for their products by the U.S. Congress (34). Recently, with the Disneyland measles outbreak, near hysteria has caused states like California to eliminate personal belief and religious exemptions for children entering school, creating untold grief in concerned parents. This paradoxically would make a study rather easy: many parents would certainly line up to include their children in a no-vaccine control group. (Many toxicity-minded physicians have been deluged with requests to provide legal medical waivers from parents opposed to vaccines (personal knowledge)). The current high rate of U.S. autism (about one in 68 children) would make studying this phenomenon easier than in the past.

Children could be recruited from areas that fluoridate and areas that don't fluoridate. Autism (and all cause morbidity/mortality) occurrences could be studied by conventional methods amongst four groups: 1) no fluoridated water/no vaccinations, 2) fluoridated water/no vaccinations, 3) conventional vaccinations/no fluoridation, 4) fluoridation/conventional vaccinations. It would be necessary to have impartial referee(s) review and control cases of vaccinated children who do not complete the full schedule of vaccines due to any potential injury or behavioral regression. Conventional vaccination means the standard recommended vaccines according to schedule for school entry according to the US Centers for Disease Control. The study should follow the children for a minimum of 5 years after the schedule is complete. The children should be studied for all cause morbidity and mortality, inclusive of autism and immune and allergic diseases such as asthma and eczema.

There would be no issues with ethics in this study population. Parents opposed to vaccination would be eager to join, and the majority already vaccinate.

\subsection{Canadian epidemiology support for the hypothesis}

In a WHO commissioned report on autism and developmental disorders, Mayada, et al. reviewed and published statistical data on autism incidence (35). USA nationwide incidence for autism (2009) was 110 per 100,000 . Close to these years were three reports from Montreal, Canada. Incidence per 100,000 for three years reported was: 21.6 (2006), 25.4 (2010), and 64.9 (2006). Only $2.7 \%$ of Quebec's people receive fluoridated water. Montreal does not fluoridate (36). There is no reason to believe that vaccination rates would be different in Montreal than the USA. Could Montreal's lack of fluoridation be contributing to the much lower incidence of local autism than in the USA? 


\subsection{Implications of the hypothesis}

With the emerging information on aluminum, safety studies using aluminum as placebo appear to be inherently seriously flawed, and perhaps biased. The hidden presence of fluoride in the mix could make a risky matter more dangerous. It is true that more boys suffer autism than girls. This hypothesis does not explain those observations, but should nevertheless not be necessary to do so. Males and females certainly differ in prevalence of diseases and may have inherent differences in physiological reactions to toxins. These differences may be explained, at least in part, by differences in hormone levels (37).

Currently there is a "dogfight" (as seen in California during the legislative hearings to remove parental discretions regarding vaccines) amongst those promoting and opposing mandatory vaccines for school, with "science" presented on both sides. (I attended the hearings where many hundreds of earnest parents lined up to oppose forced vaccination to enter schools, at a ratio of about 8:1 over those citizens favoring a vaccine mandate). But said pro vaccine "science" may be severely tainted (studies using adjuvants as "placebos" (The placebo had the same constituents as the active vaccine but without the vaccine antigen (38).) This clear methodology flaw could place millions of children in harm's way. Studies with adjuvant "placebos" may be placing the public at significant risk, in this author's opinion, by tainting the current paradigm that vaccines are safe with obviously seriously flawed methodology.

Confirmation of this hypothesis could go far in explaining vaccine study discrepancies. Confirming a fluoride link as an independent potentiator of aluminum/vaccine injury, even aside from the little controlling for aluminum, would impeach much vaccine research for lack of indispensable controls. Governments are quickly mandating vaccinations, and ASD rates are skyrocketing. Kennedy, et. al., (23), made a strong case linking environmental toxins to infant mortality in the USA. It is only logical that the link would extend to less deadly medical issues, such as autism, as well.

There is evidence in the medical literature of a similar effect with another known toxic metal - lead. For years it was thought that bone sequestered lead, thereby protecting the body. Newer data indicates that bone lead is mobilized in osteoporosis creating a lead poisoning risk factor for the woman. Moreover, lead can be also mobilized during the demineralization of pregnancy and lactation (39). It is not simply a leap of faith to consider other environmental factors potentiating the toxic effects (or release/dissolution) of aluminum particles deposited in tissues by injection. As far back as 1988, Tennakone, et al. (21) warned, "Possibly hazardous levels of aluminum could get leached from cooking utensils if fluoridated water or fluoride rich foodstuffs are used." With all the solutes in the body, Tennakone's warnings could be an understatement for in vivo combination toxin effects.

This research is urgently needed to understand and perhaps prevent a multitude of needless potential vaccine injuries, which so far are poorly understood. A fluoride connection could help explain delayed vaccine injuries, and relate to alterations in the progressive aluminum accumulation described by 
Gherardi's group. Fluoride could obfuscate what would be an otherwise clear instigator of neurological injuries.

\subsection{Conclusion}

Basic science suggests significant interaction between fluoride and aluminum, both known neurotoxins. The mix could be additive or worse synergistic. One might be the bullet, the other, the trigger.

The fluoride/aluminum connection and possible synergy in ASD needs urgent further study, especially in light of the legal stampede to government-mandated vaccines (on top of the government imposition of fluoridation). Unless and until this research is done, all vaccine safety research omitting this control should be highly questioned.

\section{Abbreviations:}

LD1: Lethal dose for $1 \%$

ASD: autism spectrum disorder

SB 277: California Senate Bill 277 passed into law in 2015 


\section{References:}

1. Kern JK, Geier DA, Sykes LK, Haley BE, Geier MR, The relationship between mercury and autism: A comprehensive review and discussion. Trace Elem Med Biol. 2016 Sep;37:824.

2. Plotkin, S., Section Editor, Gerber, J.S., Offit, PA, Vaccines and Autism: A Tale of Shifting Hypotheses, Clinical Infectious Diseases 2008; Volume 48, Issue 4:. 456-461.

3. National Academies Press (US); 2011 Aug $25 \quad$ (http://www.ncbi.nlm. nih.gov/pubmed/24624471).

4. Schubert J, Riley EJ, Tyler SA. Combined effects in toxicology - a rapid systematic testing procedure: cadmium, mercury, and lead. J Toxicol Environ Health 1978; 4: 763776.

5. http://www.accessdata.fda.gov/ scripts/cdrh/cfdocs/cfcfr/CFRSearch.cf $\underline{\mathrm{m} ? \mathrm{fr}=201.323}$

6. Aluminum Toxicity in Infants and Children, Committee on Nutrition, American Academy of Pediatrics, Pediatrics Volume 97, Number 3 March, 1996, pp. 413-416.

7. Shaw CA1, Tomljenovic L. Aluminum in the central nervous system (CNS): toxicity in humans and animals, vaccine adjuvants, and autoimmunity. Immunol Res. 2013; Jul;56(2-3):304-16.

8. Tomljenovic L1, Shaw CA. Do aluminum vaccine adjuvants contribute to the rising prevalence of autism? J Inorg Biochem. 2011; Nov;105(11):1489-99.

9. Gherardi, R., Eidi, H., Crépeaux, G., Authier, F., Cadusseau, J.,
Biopersistence and brain translocation of aluminum adjuvants of vaccines. Front. Neurol., 05 February 2015.

10. Inbar, R., Weiss, R., Tomljenovic, L., Arango, MT, Deri, Y., Shaw, C., Chapman, J., Blank, M., Shoenfeld, Y., Behavioral abnormalities in female mice following administration of aluminum adjuvants and the human papillomavirus (HPV) vaccine Gardasil, Immunol Res (2016). doi:10.1007/s12026-016-8826-6.

11. Miller, N., Aluminum in childhood vaccines is Unsafe. Journal of American Physicians and Surgeons Volume 21 Number 4 Winter 2016.

12. Perricone, C., Colafrancesco, S., Mazor R., Autoimmune/inflammatory syndrome induced by adjuvants (ASIA) 2013: Unveiling the pathogenic, clinical and diagnostic aspects. J Autoimmun 2013;47(Dec):116.

13. Choi, A., Guifan, S., Zhang, Y., Grandjean, P., Developmental Fluoride Neurotoxicity: A Systematic Review and Meta-Analysis. Environ. Health Perspectives, October 2012, vol. 120, issue 10 .

14. Choi AL, Zhang Y, Sun G, Bellinger DC, Wang K, Yang XJ, Li JS, Zheng Q, Fu Y, Grandjean P. Lifetime fluoride exposure and cognitive functions in Chinese children. Association of lifetime exposure to fluoride and cognitive functions in Chinese children: a Pilot Study. Neurotoxicol Teratol. 2015; Jan-Feb; 47:96-101. (And, Fluoride 48(2)179180 April-June 2015.)

15. Kaur T, Bijarnia RK, Nehru B., Effect of concurrent chronic exposure of 
fluoride and aluminum on rat brain. Drug \& Chem. Toxicol. (2009); 32(3): 215-21.

16. https://www.cdc.gov/ncbddd/adhd/ diagnosis.html

17. Malin AJ, Till C., Exposure to fluoridated water and attention deficit hyperactivity disorder prevalence among children and adolescents in the United States: an ecological association. Environ Health. 2015 Feb $27 ; 14: 17$.

18. Varner JA, Jensen KF, Horvath W, Isaacson RL. Chronic administration of aluminum-fluoride or sodiumfluoride to rats in drinking water: alterations in neuronal and cerebrovascular integrity. Brain Res. 1998; Feb 16;784(1-2):284-98.

19. https://bioforumconf.com/chemistry_ abs/outofhtml/80th_meeting/reactions offl_magal_saphier.html

20. https://cameochemicals.noaa.gov/ chemical/9070

21. Tennakone K, Wickramanayake S, Fernando CA., Aluminium contamination from fluoride assisted dissolution of metallic aluminium. Environ Pollut. 1988;49(2):133-43.

22. Maas RP, Patch SC, Christian AM, Coplan MJ. Effects of fluoridation and disinfection agent combinations on lead leaching from leaded-brass parts. Neurotoxicology. 2007; Sep;28(5):1023-31. Epub 2007 Jun 30.

23. Kennedy D, Seneff S, Davidson RM, Oller Jr JW, Haley BE, et al. Environmental Toxicants and Infant Mortality in the USA. Peertechz J Biol Res Dev. 2016; 1(1): 036-061.
24. Becker, K., Autism and Urbanization. Am J Public Health. 2010 July; 100(7): 1156-1157

25. Philippe Grandjean, Philip J Landrigan Neurobehavioural effects of developmental toxicity. Lancet Neurol. 2014; 13: 330-38.

26. Choi, A., Sun, G.,, Zhang, Y., Grandjean, P. Environ Developmental Fluoride Neurotoxicity: A Systematic Review and Meta-Analysis. Health Perspect; DOI:10.1289/ehp.1104912.

27. Malin AJ, Till C. Exposure to fluoridated water and attention deficit hyperactivity disorder prevalence among children and adolescents in the United States: an ecological association. Environ Health. 2015; 14: 17. (And Fluoride 48(2)i-ii April-June 2015.)

28. Van Meter, K., Christiansen, L., Delwhiche, L, et al., Geographic Distribution of Autism in California: A Retrospective Birth Cohort. Autism Res. 2010 Feb; 3(1): 19-29.

29. http://timesofindia.indiatimes.com/ city/ahmedabad/Autism-is-not-adisease/articleshow/19333810.cms

30. http://www.fda.gov/downloads/ BiologicsBloodVaccines/Vaccines/Ap provedProducts/UCM111263.pdf

31. Bach, JF., "The Effect of Infections on Susceptibility to Autoimmune and Allergic Diseases," NEJM 2002; Vol. 347:911-920, September 19, 2002.

32. Schmitz, R., Poethko-Müller, Sabine Reiter, S., Schlaud, M., Vaccination Status and Health in Children and Adolescents. Findings of the German Health Interview and Examination Survey for Children and Adolescents (KiGGS). Dtsch Arztebl Int. 2011 Feb; 
108(7): 99-104.

33. Wenger, OK, McManus, MD, Bower, JR, Langkamp, DL, Underimmunization in Ohio's Amish: Parental Fears Are a Greater Obstacle Than Access to Care, Pediatrics. 2011 Jul;128(1): 79-85.

34. 42 U.S.C. $\S \S 300 a a-1$ to $300 a a-34$

35. Elsabbagh, M., Divan, G., Koh, YJ, Kim, Y., et al., Global Prevalence of Autism and Other Pervasive Developmental Disorders, Autism Res. 2012 Jun; 5(3): 160-179. Published online 2012 Apr 11.

36. Tchouaket, E., Brousselle, A Fansi, A., Dionne, PA, Bertrand, E., Fortin, C., The economic value of Quebec's water fluoridation program, J Public Health 2013; 21:523-533.

37. Nicolson, T., Mellor, H.,Trends, R., Gender differences in drug toxicity, Pharmacological Sciences March 2010; 31(3):108-14 62.

38. Guillermo, M., Pérez-Schael, I., Velázquez, F., Albate, H., Breuer, T., et al., Safety and Efficacy of an Attenuated Vaccine against Severe Rotavirus Gastroenteritis. N Engl J Med 2006; 354:11-22.

39. Silbergeld EK, Schwartz J, Mahaffey K., Lead and osteoporosis: mobilization of lead from bone in postmenopausal women., Environ Res. 1988 Oct;47(1):79-94. 